\title{
THE PART PLAYED BY WOODLAND MOSQUITOES OF THE GENUS Ä̈DES IN THE TRANSMISSION OF MYXOMATOSIS IN ENGLAND
}

\author{
BY R. C. MUIRHEAD-THOMSON* \\ Infestation Control Division, Ministry of Agriculture, \\ Fisheries and Food, Tolworth, Surrey \\ (With Plate 14, and 1 Map in the Text) \\ INTRODUCTION
}

The first outbreak of myxomatosis in England was confirmed on 13 October 1953 at Bough Beech, near Edenbridge in west Kent. Between that time and the end of the year seven more outbreaks occurred in different-and usually widely separated-localities in south-east England, in the counties of Kent, Sussex, Essex and Suffolk. The history of these outbreaks and the subsequent spread of the disease has been fully discussed in several reports, in particular those of Andrewes (1954), Ritchie, Hudson \& Thompson (1954) and Armour \& Thompson (1955).

Although the disease only spread slowly from these outbreak centres during the following two or three winter months, there was no evidence of its dying out, and it seemed quite possible therefore that a much more rapid spread might be expected during the spring and summer. Early in 1954 an investigation of possible insect vectors was initiated, and attention was concentrated on the original outbreak centre near Edenbridge. During the course of 1954, while this entomological work was going on, a careful survey of the spread and distribution of the disease in this area was being carried out by my colleague C. J. Armour, who was able to obtain a unique record of the natural spread of disease in the almost complete absence of human interference (Armour \& Thompson, 1955).

The area in which the entomological work was done-about 100 square mileswas not completely covered by the disease till the end of summer, 1954, the average rate of spread southwards from Bough Beech during spring and summer being less than 1 mile a month. This slow rate of spread allowed unusual opportunities for studying the possible role of different mosquitoes as vectors of myxomatosis, as it was possible to have a continuous series of observations in places in which the disease was actually present. In the course of the work on the laboratory transmission of myxoma virus by these mosquitoes, infection of mosquitoes was originally detected by means of direct feeding on a healthy host. Later this was supplemented by standard methods of virus recovery, grinding and inoculation, which were carried out at the National Institute for Medical Research by Dr C. H. Andrewes, to whom I am greatly indebted for this and other invaluable advice and assistance.

* Present Address : Liberian Institute of the American Foundation for Tropical Medicine, Harbel, Liberia. 


\section{THE $A E D E S$ MOSQUITOES AND THEIR DISTRIBUTION}

Preliminary surveys of larval and adult mosquitoes in this well-wooded area showed that while several different species (such as Anopheles claviger Meigen., A. maculipennis messeae Meigen., A. plumbeus Stephens., Theobaldia annulata Schrank., and T. (Culicella) morsitans Theobald) were present in small numbers in the Edenbridge area, by far the most dominant mosquitoes both as larvae in late winter and early spring and as adults in summer were the woodland Aëdes (A.cantans Meigen. and A.annulipes Meigen.). These Aëdes which breed in enormous numbers in woodland pools were particularly abundant in a few specially suitable localities in this area (see sketch map). In this survey, covering roughly 100 square miles, these Aëdes were present in small numbers in many woodland localities, but there was really dense breeding in only three places where innumerable woodland pools were swarming with larvae in spring and where there was a high density of persistently biting mosquitoes in the summer. It is mainly in these three woodland areas, Bough Beech (the original outbreak centre), Markbeech and Chandlers Wood that the following observations were made.

The general habits of $A$. cantans and $A$. annulipes have recently been summarized by Shute (1954). Eggs laid in the autumn produce larvae in the latter part of the winter. By March and April woodland pools are swarming with larvae. Between June and September adults bite viciously in the woods, but there is no breeding during that time as these mosquitoes are single brooded, and the woodland pools are free of larvae throughout the summer. In the present investigation pupae appeared in numbers in the first week of May, and adults began to appear from mid-May onwards. Biting activity was intense during the following four months, and in one place (Chandlers Wood) continued till mid-October.

Although typical $A$. cantans and $A$. annulipes can be distinguished without much difficulty and have different breeding habits, many ill-defined or intermediate adult forms were encountered. In view of this and of the fact that the biting habits and relation to myxomatosis of the two species appear to be similar, it has been convenient on occasions to refer to Aëdes of the cantans-annulipes group, especially when dealing with samples containing a high proportion of indeterminate forms. A. cantans was the dominant species in Bough Beech, while in Chandlers Wood both species were present in about equal numbers.

In one locality in the study area, namely, Domewood Lake (see sketch map) very high numbers of $A$. cinereus Meigen. were encountered, along with small numbers of $A$. annulipes. A cinereus is also a single-brooded species which bites man viciously after dark as well as during the day. Myxomatosis did not reach this area till the end of September 1954, by which time the summer brood of cinereus was dying out and it was not therefore possible to study its biting habits at a time when the disease was present.

Apart from these three species of Aëdes other British species appeared to be rare in this particular study area. But these conditions are by no means typical of the south of England, and there are many localities even in Surrey where other species of Aëdes are locally abundant (Shute, personal communication). As far as density 
of mosquitoes is concerned, however, there are probably few places where Aëdes occurs in such numbers as in some of these woodlands in the Edenbridge area with a biting or attack rate on man approaching 1000 per hour at peak periods.

A few miles north of Edenbridge the land starts rising to the North Downs, where suitable mosquito breeding places are scarce, and as a result this belt is virtually free of these woodland Aëdes.

\section{BITING ACTIVITY OF AËDES CANTANS AND A. ANNULIPES}

The main biting activities of these mosquitoes in relation to man are well known, and in the present investigation there were many occasions when the persistent attack of these mosquitoes became almost intolerable. The fringes of many of

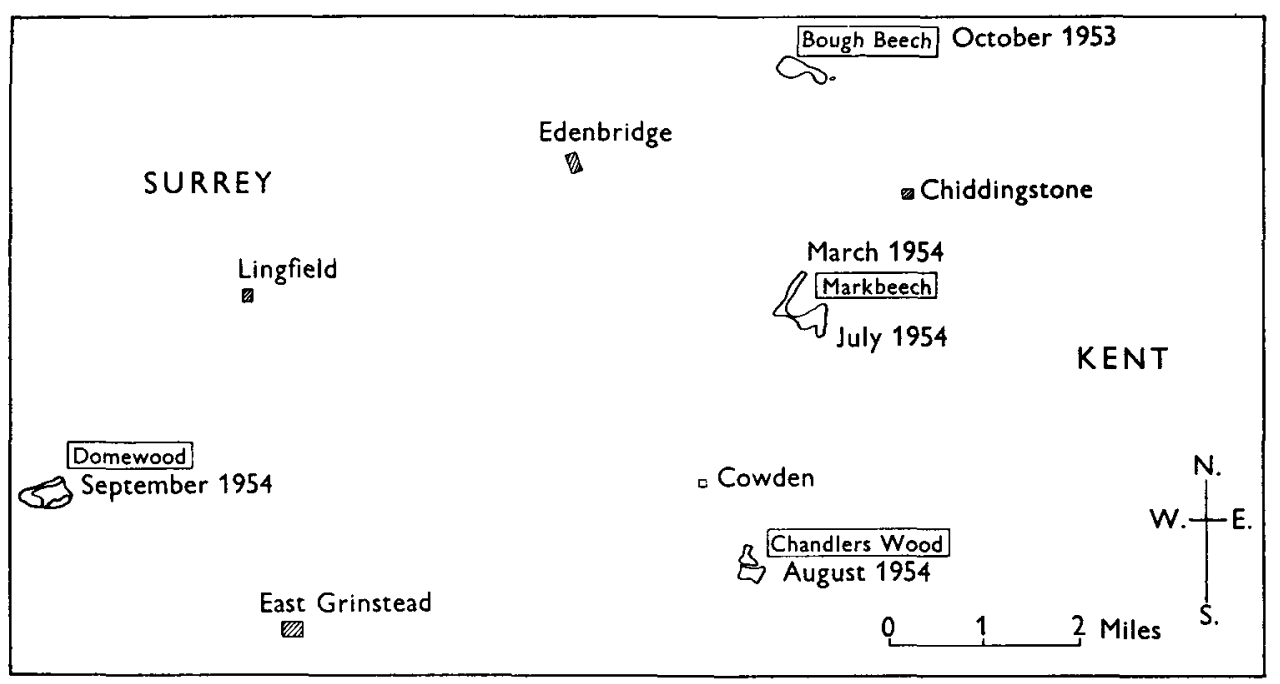

Sketch map of the Edenbridge area (Surrey and Kent), showing distribution of Aeddes-infested woodlands in relation to the spread of myxomatosis from the outbreak centre of Bough Beech, 1953-4.

Bough Beech: Mainly A. cantans.

Markbeech: Mainly cantans but also $A$. annulipes.

Chandlers Wood: $A$. cantans and $A$. annulipes in about equal numbers.

Domewood: Mainly $A$. cinereus, with a few $A$. annulipes.

Showing dates when the disease was first reported in these areas.

these woodlands were heavily infested with rabbits, and it appeared reasonable to expect-particularly in view of the work in Australia-that rabbits would form a more regular and easily available source of blood than the occasional human visitor. However, all the methods of investigation used were unable to reveal anything more than a very low degree of attraction to rabbits on the part of the mosquitoes.

When a captive wild rabbit or a tame rabbit is exposed in these woods and closely watched to see what mosquitoes attack it, it is quite easy to demonstrate mosquitoes biting it. However, there is no doubt that the great majority of mosquitoes which do attack the rabbit under these conditions have been primarily 
attracted to man or disturbed by his presence. In order to find out what mosquitoes were attracted to a rabbit on its own the following methods were used:

(1) An isolated rabbit was visited at intervals of 5 or $10 \mathrm{~min}$, quickly inspected and then left alone for a further period. Using this method both by day and by night it soon became clear that at a time when man was being persistently attacked, the rabbit on its own either remained completely free of mosquito attacks or at most only attracted one or two. These observations were first carried out in the unusually cool summer of 1954 and were repeated in the hot summer of 1955 , at temperatures of $75-80^{\circ} \mathrm{F}$., with similar results. On one occasion when $100-120$ Aëdes were taken attempting to bite man, only four were seen attempting to bite an isolated rabbit during the same period. On another occasion not a single Aëdes was attracted to a captive wild rabbit at a time when man was being attacked at the rate of eighty-two in $5 \mathrm{~min}$. or approximately 1000 per hour.

(2) Rabbit-baited mosquito traps were left in Aëdes-infested woodlands by day and by night, but no mosquitoes were found either in the trap or in the exit cages. These negative results by themselves are not conclusive, however, as Aëdes may have been reluctant to enter this covered-in type of trap.

(3) The most convincing method of demonstrating the natural feeding activities of these woodland mosquitoes would have been to collect engorged mosquitoes from their resting places and to identify the source of blood meals by means of precipitin tests. This technique was used very successfully by the Australian workers (Lee, Clinton \& O'Gower, 1954), who apparently had no difficulty in finding gorged mosquitoes on the banks of rivers and creeks. In the present work various methods used, including sweeping and searching, have failed to disclose engorged mosquitoes in Aëdes-infested woodland, apart from those which had just fed on the human collector. Nor were any mosquitoes found in lobster-pot types of exit traps installed in the mouths of occupied burrows.

Under conditions of close confinement in the laboratory-as, for example, in a standard $1 \mathrm{ft}$. cube mosquito cage $-A$. cantans and $A$. annulipes will feed readily on anaesthetized rabbits or on rabbits practically immobilized by disease, but they have difficulty in feeding on active healthy rabbits.

Like many other aspects of the myxomatosis problem this question of the normal source of blood meals of woodland mosquitoes is evidently sufficiently obscure to require a full-time investigation. The methods of observation used in (1) above suggest a very low degree of attraction to rabbits. In woodland areas which had been cleared of rabbits during the summer of 1954 the density of Aëdes in 1955 appeared to be as high as ever, suggesting that there was no great dependence on rabbits as a normal source of blood meal.

Although direct observation and trapping only provided information of a negative character the presence of myxomatosis made it possible to study the relationship between $A \ddot{e} d e s$ and rabbits in another way, namely, by the search for wild-caught Aëdes naturally infected with myxoma virus and by the use of 'sentinel' rabbits in areas of active transmission. The use of these methods will be described later. 


\section{AEDES CANTANS AND A. ANNULIPES AS LABORATORY VECTORS OF MYXOMATOSIS}

Although $A$. cantans and $A$. annulipes appear reluctant to feed on normal healthy rabbits, both in the field and in the laboratory, in captivity they feed readily on immobilized rabbits, whether normal anaesthetized rabbits, or rabbits in the comatose stage of myxomatosis.

Large batches of wild-caught $A$. cantans taken from an area which had been free from rabbits for many months were exposed to advanced myxomatous rabbits in a $1 \mathrm{ft}$. cube cage. They fed readily mainly on the nose and round the eyes. Engorged mosquitoes were kept in the laboratory and provided with cotton-wool moistened with dilute sugar solution. At intervals the infectivity of the mosquitoes was tested by exposing healthy anaesthetized rabbits to the mosquitoes in the cages, or by feeding small batches of mosquitoes on a normal rabbit's ear. The period between the infective blood meal and the first exposure to a healthy rabbit varied from 5 to 36 days, during which period the mosquitoes were maintained on sugar solution alone.

Using nine batches of infected mosquitoes, positive results were obtained after the following periods: 5, 7, 9, 9, 15, 21, 25 and 36 days. Although Aëdes in the laboratory can be kept alive for a much longer period than 36 days, it is found that the sugar solution necessary to keep them alive also has the effect of making the mosquitoes sluggish and reluctant to take a blood meal. As far as infection by bite is concerned therefore it would be difficult to demonstrate infectivity beyond the maximum of 36 days recorded. Beyond that period grinding and inoculation of mosquitoes might have revealed further persistence of virus, but that was not done. In this series of experiments only one negative result was obtained when a batch of mosquitoes which had fed on an advanced myxomatous rabbit were exposed 7 days later to the first healthy host; five mosquitoes gorged but failed to infect the rabbit.

In July of the following summer, a batch of 37 A. cantans-annulipes infected in a similar manner was submitted for virus titration 23 days after the infective blood meal, with negative results. This apparent discrepancy may possibly have been due to the latter batch being kept at a much higher mean temperatureabout $25^{\circ} \mathrm{C}$.- than those of the previous summer-about $16^{\circ} \mathrm{C}$. Clearly both methods of testing infectivity should have run concurrently-as was done later in the case of Anopheles atroparvus. Although the biting experiments indicate that Aëdes may remain infective for periods up to 36 days after the infective blood meal, these observations really need repeating and amplifying.

$A$. cantans and $A$. annulipes are single brooded species, and those females which emerge in May presumably live for several months, during which time they may feed more than once. In the laboratory, Aëdes which had already fed on and infected a first healthy host were most reluctant to feed on a second healthy host. In four experiments involving a total of eleven mosquitoes which successfully gorged on a second healthy host, no infection was produced in the rabbits. These figures suggest that the infected Aëdes-unlike Anopheles 
atroparvus - may lose its infectivity after a blood meal, and be unable to infect a second host, but more figures would be required to put this suggestion on a sound basis.

- As described above, Aëdes in captivity feed mainly round the eyes and on the nose of anaesthetized rabbits, and less frequently on the feet. In the infected rabbit the first symptoms are distinctly different from those which are normally produced either by the bite of rabbit fleas (Spilopsyllus cuniculi) or by the bite of Anopheles atroparvus. Rabbits infected by Aëdes show a very early appearance of tumours on the nose, the lesions becoming prominent and well developed by the time the eyelids have become swollen and the discharge has become profuse. Additional lesions on the feet are more frequently seen when infection is by the bite of Aëdes. Observations on normal rabbits in the field also indicate that the nose is a prominent biting site, if not the main one, but no diseased wild rabbits showing unusually prominent nasal lesions were seen in the study area.

\section{INFECTED $A E ̈ D E S$ IN NATURE}

(1) Recovery of virus. In the Edenbridge area two woodlands heavily infested with $A$. cantans-annulipes had not yet been reached by the disease by the time observations started there in March 1953. Close watch was kept on a thriving colony of rabbits on the south fringes of Markbeech Wood, and the disease finally appeared there at the beginning of July. From this time onwards $A$. cantans were collected from these woods and tested by feeding batches of roughly 100 on anaesthetized healthy rabbits, with the following results:

$\begin{array}{ccc}\text { Date } & \text { No. of mosquitoes fed } & \begin{array}{c}\text { Results of feeding } \\ \text { on healthy rabbit }\end{array} \\ \text { 23. vii. } 54 & 90 \mathrm{~A} \text {. cantans } & \text { Positive } \\ \text { 26. vii. } 54 & 156 \mathrm{~A} \text {. cantans } & \text { Positive } \\ \text { 29. vii. } 54 & 98 \mathrm{~A} \text {. cantans } & \text { Positive } \\ \text { 6. viii. } 54 & 188 \mathrm{~A} \text {. cantans } & \text { Positive } \\ \text { 14. viii. } 54 & 84 \mathrm{~A} \text {. cantans } & \text { Negative }\end{array}$

In all these cases the rabbits infected by mosquito bite showed early development of tumours on the nose-one of the main biting sites. When the disease was first known to be present in this area a tame rabbit was exposed and was seen to be bitten by one or two Aëdes originally attracted to the human observer. The rabbit later developed myxomatosis with a characteristic nose tumour.

The disease was first reported in Chandlers Wood area about mid-August, but it may have been there longer. From that time onwards batches of wild-caught $A$. cantans and $A$. annulipes were collected in the wood, and before being tested for natural infections by the method described above were lightly anaesthetized for identification. Those with distinct characters of $A$. cantans and $A$. annulipes were separated while the remainder with indeterminate characters were combined as $A$. cantans-annulipes. 
The results from Chandlers Wood were as follows:

Date
18. viii. 54
1-6. ix. 54
8. ix. 54
15. ix. 54

No. of mosquitoes fed

96 A. cantans-annulipes

$25 A$. cantans

15 A. annulipes

24 A. cantans

$23 \mathrm{~A}$. annulipes

27 A. cantans-annulipes
Results of feeding

on healthy rabbit

Positive

Positive

Negative

Negative

Positive

Negative

Batches of Aëdes caught on 14, 17 and 20 September - totalling about 150 mosquitoes-were sent to Mill Hill for routine virus recovery, but the results were negative.

The results obtained in the biting experiments agree with those obtained at Markbeech above in showing the repeated recovery of batches of wild-caught Aëdes naturally infected with myxoma virus at a time when the disease was known to be present. They show, in addition, that where the characters could be clearly differentiated, natural infections have been recorded in both $A$. cantans and A. annulipes.

From these findings it is clear that, although $A$. cantans and annulipes appear to be little attracted to normal healthy rabbits, presumably some can feed on diseased and immobilized rabbits in nature (in the same way as they do in the laboratory) and are thus able to pick up the infection. Before discussing further the implication of these findings, evidence from other sources will have to be described.

(2) Sentinel rabbits. As part of the general plan for studying the spread of myxomatosis from the first outbreak in Bough Beech near Edenbridge, standard hutches containing 'sentinel' rabbits were set up both in areas where the disease was active and in places which had not yet been reached by the disease (Armour \& Thompson, 1955). These hutches were approximately $2 \times 2 \times 2 \mathrm{ft}$. and were enclosed except for the front which consisted of a door fitted with wide-mesh wire netting. These hutches containing domestic rabbits were fixed about $5 \mathrm{ft}$. from the ground as a means of protection against predators and also as a protection from infection by fleas and other non-flying vectors of myxomatosis. As the hutches were constantly occupied and moved from time to time to areas in which the disease was still present, it was confidently expected that contraction of the disease by the 'sentinel' rabbit would indicate or confirm the presence of flying vectors of the disease. Although these 'sentinel' rabbit hutches were installed over a wide area, under a variety of conditions, without exception the rabbits remained healthy despite months of exposure (Armour \& Thompson, 1955).

In the present entomological investigation special attention was given to standard sentinel hutches set up in Markbeech and Chandlers Wood, areas of high Aëdes density. A sentinel rabbit was installed at Markbeech about 3 weeks after the disease had first been reported, and at a time when batches of infected Aëdes were being taken regularly in this woodland. After 2 months of continuous exposure the rabbit remained free of infection. On the other hand (as already described above) when the disease was first known to be present in the area a tame 
rabbit, exposed in the same part of woodland and seen to be bitten by one or two Aëdes originally attracted to the human observer, later developed myxomatosis.

At Chandlers Wood a standard sentinel rabbit was exposed under similar conditions, at a time when naturally infected $A$. cantans and $A$. annulipes were present in the wood, and when diseased rabbits were still being reported from this area. The rabbit remained free from infection after 5 weeks of exposure from midSeptember until the end of October.

In the frequent visits of inspection to these sentinel rabbits Aëdes were never seen in their hutches or attempting to bite them, confirming previous observations about the low degree of attraction of healthy rabbits to these mosquitoes. The interpretation of these findings at that time appeared to be as follows. Despite the low attraction to rabbits a certain amount of feeding evidently takes place on those advanced myxomatous rabbits which are exposed in the woods in a comatose condition. Although some mosquitoes pick up the infection in this way, there seems little indication that they can pass it on to other rabbits, even to tame domestic rabbits exposed in hutches. If, however, a human who has attracted a large number of hungry Aëdes takes up a position close to a rabbit exposed in the open, the rabbit is very likely to be bitten and to contract the disease.

There still remained the possibility, however, that the standard closed-in hutch with wire-netting front might serve as an additional discouragement to the few Aëdes which are attracted to rabbits. Accordingly, a different kind of sentinel cage was set up in Chandlers Wood (Pl. 14). This was approximately $6 \times 6 \mathrm{ft}$. and $4 \mathrm{ft}$. high; completely open at the top, and with the sides and floor of large-mesh wire netting. In one corner a little overhead shelter was provided for the sentinel rabbit, which was otherwise completely exposed. The cage was set up in the wood at a height of about $5 \mathrm{ft}$. from the ground.

A sentinel rabbit was installed in this open cage on 9 September, at a time when infected Aëdes were being recovered from the wood. It must have been bitten by infected mosquitoes within the first 2 or 3 days, as the first symptoms of disease appeared on the 17th. The rabbit was removed and replaced by a second healthy rabbit which remained free of infection during a further period of exposure of 5 weeks, during which time, however, there were no further records of naturally infected Aëdes occurring in the woods. The fact that the very first sentinel rabbit to be exposed in an open cage became infected so quickly at a time when, and under conditions in which, sentinel rabbits in standard hutches remained healthy after long exposure suggests that, despite the very low degree of attraction which rabbits provide for mosquitoes, there is a significant difference in the degree of biting in the two kinds of cage. Although the amount of biting on normal healthy rabbits appears to be sufficiently small to ensure that rabbits in standard hutches remain free from infection, the slight extra attraction of the sentinel rabbit in the open cage may expose it to the bite of the occasional infected mosquito. 


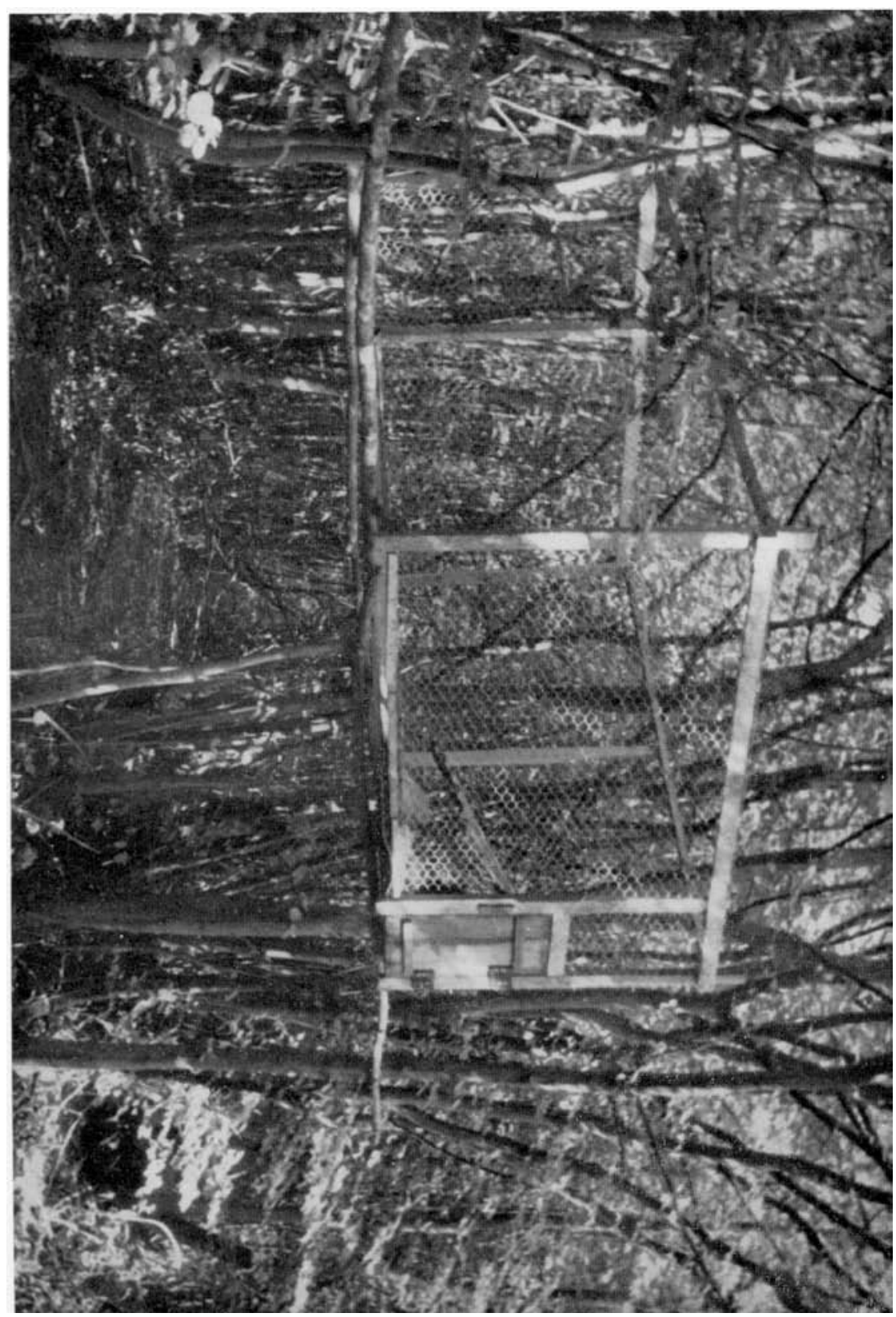

(Facing $p .468$ ) 


\section{OBSERVATIONS ON AËDES CINEREUS}

A. cinereus was recorded in very large numbers at Domewood Lake, near East Grinstead (see sketch map). In 1954 myxomatosis was first reported in this area in the last week of September at a time when this mosquito was becoming scarce.

In the summer of 1955 high catches of $A$. cinereus were taken from mid-June onwards when mosquitoes were biting humans viciously by day as well as after dark. Observations on captive wild rabbits showed that when the isolated rabbit was only visited at intervals and then quickly inspected, it did not attract $A$. cinereus at a time when humans were being persistently attacked. For example, in an after-dark collection in $30 \mathrm{~min}$., the following mosquitoes were taken attempting to bite:

$\begin{array}{lcc} & \text { Man } & \text { Rabbit } \\ \text { A. cinereus } & 57 & 0 \\ \text { A. annulipes } & 7 & 0\end{array}$

When the rabbit was closely watched for a longer period, $A$. cinereus attracted by the human host readily bit the rabbit, most feeding taking place (in a captive wild rabbit) on the top of the head and on the ears. Under similar conditions with the human host close by, $A$. cantans and $A$. annulipes are also attracted to the rabbit but in much smaller numbers, and they appear to have more difficulty than $A$. cinereus in taking a full blood meal on that animal.

No great difficulty was encountered in persuading wild-caught $A$. cinereus to feed on advanced myxomatous rabbits in captivity, but they appeared reluctant to take subsequent blood meals on healthy anaesthetized rabbits. Two successful transmissions were based on single bites, as follows:

Interval after
infective blood meal
15 days
15 days

No. of
cinereus biting
1
1

Result and
incubation period
Positive, 10 days
Positive, 6 days

\section{DISCUSSION}

The study of the woodland Aëdes, particularly $A$. cantans and $A$. annulipes, as vectors of myxomatosis in England has raised the problem of vectors of insectborne animal virus diseases in general. Two main findings at first appear contradictory: the recovery of infected mosquitoes in several batches of wild-caught Aëdes collected in areas where the disease was known to be present, and observations which indicated that the same Aëdes is attracted to rabbits only to a very limited extent. In investigations of this kind the recovery of virus from wildcaught mosquitoes is usually regarded as highly significant incrimination as the natural insect vector. But in the present investigation it appears that while Aëdes must feed to a certain extent on diseased rabbits (which are exposed and comatose in the later stages of the disease) because they pick up the infection, there is very little indication that in nature these infected mosquitoes pass on the disease to healthy wild rabbits. Even passive domestic rabbits exposed to the bites of Aëdes in mosquito-infested woodlands appear to have very little attraction for 
mosquitoes; and captive wild rabbits under similar conditions seem to be no more attractive.

Under certain conditions, despite their low attraction, domestic rabbits exposed in open unprotected cages may acquire myxomatosis by the bite of wild infected Aëdes; but in the same locality domestic rabbits in closed-in hutches, which still allow free ingress of mosquitoes through wide-mesh wire netting, have without exception remained healthy after months of exposure in areas where the disease was present. This state of affairs is like that disclosed a few years ago in studies on jungle yellow fever in Uganda, where it was found that susceptible sentinel monkeys exposed in areas where virus was known to be circulating remained free from infection for months because the responsible mosquito ( $A$. africanus) would not enter their cages. When the monkeys were exposed on open platforms they readily picked up infections from the bite of mosquitoes.

In the myxomatosis work no difference has been observed in the frequency of biting on rabbits in closed-in hutches and on those in open wire-netting cages. We can infer a slightly greater attraction to the exposed rabbits only because they alone have become infected under natural conditions by the bite of infected mosquitoes.

With regard to the apparent ease with which Aëdes picks up the infection in nature, observations in the field show that diseased wild rabbits are no more attractive to $A \ddot{e} d e s$ than are healthy rabbits, domestic or wild; and again we can only infer that the few mosquitoes which are attracted to rabbits of any kind find it easier to feed on a practically motionless diseased rabbit than on an active healthy one, just as they do under laboratory conditions.

The rate of spread of the disease through $A \ddot{e} d e s$-infested woodland cannot be compared with that in mosquito-free areas, mainly because $A \ddot{e} d e s$-infested woodlands are not usually continuous over long distances. It is interesting, however, that one of the slowest rates recorded - about 4 months to cover 1 mile-was in an almost continuous stretch of $A \ddot{e} d e s$-infested woodland; but, since nearly 3 of these 4 months fell at a time of year when $A \ddot{e} d e s$ had not yet appeared in numbers, this observation is not of any great significance.

\section{SUMMARY}

1. Myxomatosis was first recorded in England in October 1953 and persisted over the following winter. It was anticipated that an epizootic, similar to those in Australia, would develop during the spring or summer of 1954 and that mosquitoes might be the principal vectors. A study of the sylvan mosquitoes in the area of the first myxomatosis outbreak was therefore made, from April 1954 onwards.

2. These mosquitoes (Aëdes spp.) overwinter as larvae, pupate in early May and are adult from mid-May to September. Throughout this period, in 1954, myxomatosis spread slowly in the study area and infected rabbits were abundant.

3. Despite the presence of large numbers of Aëdes (particularly A. cantans and $A$. annulipes) and their persistent attacks upon man, the mosquitoes (except in one case) were not attracted to healthy domestic rabbits exposed in the woods. Aëdes 
can have little, if any, part in the spread of myxomatosis. Observations made in the cool summer of 1954 were confirmed in the hot summer of 1955 .

4. Engorged mosquitoes (apart from those which had just fed on the human collector) were never found, so precipitin tests could not be made. The source from which these woodland mosquitoes normally obtain their blood meals remains a mystery.

5. In the laboratory, the $A \ddot{e} d e s$ were reluctant to feed on normal, healthy rabbits but fed readily (round the eyes and on the nose) on normal anaesthetized rabbits or comatose myxomatous rabbits. Biting experiments indicated that Aëdes may remain infective for up to 36 days after an infective blood meal.

6. Infected $A \ddot{d} d e s$ were recovered from woods containing myxomatous rabbits, and tame rabbits infected by the bites of these mosquitoes developed myxomatous tumours on the nose. Although some Aëdes were thus feeding on wild myxomatous rabbits, the evidence that the mosquitoes did not feed on healthy rabbits indicates that $A \ddot{e} d e s$ were of negligible importance as vectors of myxomatosis.

\section{REFERENCES}

ANDrewes, C. H. (1954). Nature, Lond., 174, 529.

Armour, C. J. \& Thompson, H. V. (1955). Ann. appl. Biol. 43, 511.

Lee, D. J., Chinton, K. J. \& O'Gower, A. L. (1954). Aust. J. exp. Biol. med. Sci. 7, 282.

Ministry of Health (1954). Memorandum on Measures for the Control of Mosquito Nuisances in Great Britain. London: H.M.S.O.

Ritchie, J. N., Hudson, J. R. \& Thompson, H. V. (1954). Vet. Rec. 66, 796.

Shote, P. G. (1954). See Ministry of Health.

\section{EXPLANATION OF PLATE}

Plate 14. Open-type sentinel rabbit cage as distinct from standard sentinel hutch.

(MS. received for publication 5. v. 56) 